\title{
Kinetic and thermodynamic studies for fluoride removal using a novel bio-adsorbent from possotia (Vitex negundo) leaf
}

Pranjal Saikia*, Ranjan Kumar Bharali and Hemanta Kumar Baruah

\begin{abstract}
Background: Possotia leaf powder (PLP), a novel biosorbent obtained from a locally available wild plant with environment friendly and low cost nature, has found to be effective to remove fluoride from fluoride contaminated drinking water.

Methods: The kinetic and thermodynamic parameters for the adsorption have been studied. Its fluorideabsorption efficiency is found to be nearly $75 \%$ at natural $\mathrm{pH}$ range and is affected by the parameters likecontact time, absorbent dose, solution temperature and initial fluoride concentration.

Results: The optimum contact time and absorbent dose were found to be $120 \mathrm{~min}$ and $3 \mathrm{gm} / \mathrm{L}$, respectively. Langmuir, Freundlich and Temkin isotherm are studied through this experimental data and found to be well followed. The adsorption kinetics data were fitted to pseudo first order, pseudo second order, and intraparticle diffusion models and was best fitted for pseudo second order model.

Conclusions: The thermodynamic study points out the efficiency of this bio-adsorbent at low temperatureindicating the physical nature of adsorption with weak adsorbent-adsorbate force of attraction. By studyingenthalpy, entropy and Gibb's free energy via van't Hoff plot, it was observed that the adsorption process wasfavorable and exothermic in nature.
\end{abstract}

Keywords: Vitex negundo, Possotia leaf powder, Kinetics, Isotherm, Bio-adsorbent

\section{Background}

Water is life, but we are still unable to make healthy drinking water available and affordable to all. Waste or contaminated water from any source must ultimately return to the natural water reservoir. A large number of people depend heavily on underground water due to lack of other water resources. People in the world are suffering as $80 \%$ of the diseases come from ill or deteriorated water, which is threatening for human life (Mamba et al., n.d.). Fluoride is one such life-threatening water contaminant. Its gaseous form is a very powerful oxidizing agent. Naturally, fluoride exists as a very reactive fluoride ion, and its natural abundance by weight in the Earth's crust ranges from $0.065-0.09 \%$ (Mondal et al., n.d.-a). The World

\footnotetext{
* Correspondence: pranjalsaikia@gauhati.ac.in

Gauhati University Faculty of Technology, Guwahati, Assam, India
}

Health Organization (WHO) announced the acceptable range of fluoride in drinking water as $1-1.5 \mathrm{mg} / \mathrm{L}$ (Swain et al., n.d.; Mohan et al., n.d.).

Intake of fluoride from drinking water at the level of $1 \mathrm{mg} / \mathrm{L}$ enhances bone development and prevents dental carries. Exceeding the limit of fluoride intake may lead to dental and skeletal fluorosis. The main constituent of teeth and bone is hydroxyl apatite $\left(\mathrm{Ca}_{10}\left(\mathrm{PO}_{4}\right)_{6}(\mathrm{OH})_{2}\right)$ and fluoride can substitute the hydroxide ion within the hydroxyl apatite crystal structure to form fluorapatite $\left(\mathrm{Ca}_{5}\left(\mathrm{PO}_{4}\right)_{3} \mathrm{~F}\right)$, which makes teeth and bones denser, harder, and more brittle (Yu et al., n.d.). Young children are the most susceptible as dental enamel and skeletal formation is most active during early childhood (Levin et al., n.d.). Moreover, excessive fluoride intact may interfere in DNA synthesis (Bhatnagar et al., n.d.). 
Therefore, researchers are trying to focus on various defluoridation processes. The most commonly used methods for defluoridation of drinking water are reverse osmosis, precipitation, membrane filtration, ionexchange, etc. (Yadav et al., n.d.). Among these, adsorption is considered as the best method for its low maintenance cost and effectiveness towards fluoride removal even at low concentrations (Gandhi et al., n.d.). Hence, researchers have focused on locally available bioadsorbents like Moringa oleifera (drum stick), tulsi, tamarind seed, tea ash (Mondal et al., n.d.-b), babool bark (Mamilwar et al., n.d.), banana peel (Bhaumik \& Mandal, 2016), neem leaf, kikar leaf (Kumar et al., n.d.), papal leaf (Ramanjaneyulu et al., n.d.), red mud, fly ash, rice husk ash, and maize ash (Waghmare \& Arfin, n.d.).

Vitex negundo, popularly known as possotia trees in the North Eastern Region of India, belong to the family Lamiaceae which are easily available in Assam, India, and are known for their medicinal properties. Studies have shown that chemicals isolated from the plant have potential anti-inflammatory, antibacterial, antifungal, and analgesic activities (Dharamasiri et al., n.d.; Gupta \& Tandon, n.d.). Moreover, local people use it as vegetable leaf for treatment of rheumatism and deworming. Use of its bark for defluoridation was already reported (Suneetha et al., n.d.). But as it is a herb-like plant, many plants will be required for the preparation of the bioadsorbent. Therefore, it is imperative to study if this particular leaf could be used for the wastewater treatment. With this background, this study was undertaken and a detailed kinetic and thermodynamic interpretation of the process involved has been presented in this manuscript.

\section{Methods}

\section{Preparation of required solutions}

Stock solution of the adsorbate $\mathrm{NaF}$ of concentration $100 \mathrm{mg} / \mathrm{L}$ is prepared by dissolving $0.22 \mathrm{~g}$ of $\mathrm{NaF}$ in $1.0 \mathrm{~L}$ of distilled water. SPADNS solution is prepared by dissolving $958 \mathrm{mg}$ SPADNS [sodium 2-(parasulfo-phenylazo)-1,8 dihydroxy-3,6 naphthalene disulfonate] in $500 \mathrm{~mL}$ of distilled water. The zirconium-oxychloride solution is prepared by first dissolving $133 \mathrm{mg}$ of zirconium-oxychloride octahydrate $\left(\mathrm{ZrOCl}_{2} \cdot 8 \mathrm{H}_{2} \mathrm{O}\right)$ in $25 \mathrm{~mL}$ of distilled water, then adding $350 \mathrm{~mL}$ of concentrated $\mathrm{HCl}$ and making the total volume of the solution up to $500 \mathrm{~mL}$ with distilled water. By mixing equal volume of SPADNS and zirconium-oxychloride solution, the SPADNS reagent is prepared which is used in the experiments.

A stock solution of $0.05 \mathrm{M}$ copper (II) bisethylenediamine complex is prepared by mixing $50 \mathrm{~mL}$ of $0.1 \mathrm{M}$ $\mathrm{CuCl}_{2}$ solution with $102 \mathrm{~mL}$ of $1.0 \mathrm{M}$ ethylene diamine solution and is used to determine the cation exchange capacity of the bio-adsorbent.

\section{Preparation of possotia leaf powder}

The bio-adsorbent possotia leaf powder is prepared from the matured leaves of the possotia tree. The leaves are collected, cleaned thoroughly, and dried for 3-4 days. The dried leaves are crushed into fine powder by using a mechanical grinder. The resultant powder is sieved and fractionated using a series of sieves with different sizes. The powder is then again dried in an air oven at $60-70^{\circ}$ $\mathrm{C}$ for $12 \mathrm{~h}$ and washed with distilled water to remove all the color pigments so that it will not interfere in spectroscopic studies. Then the sample is kept at room temperature and used for further experiments.

\section{Adsorption experiments}

In a $100-\mathrm{mL}$ conical flask, the required amount of possotia leaf powder (PLP) is taken and $50 \mathrm{~mL}$ of $\mathrm{NaF}$ solution of a particular concentration is added. It is then agitated in a shaker at a constant speed for some time. As soon as the adsorption is over, the mixture is filtered off and the amount of un-adsorbed fluoride is estimated spectrophotometrically by SPADNS method at $\lambda_{\max }=$ $570 \mathrm{~nm}$ (Bharali \& Bhattacharyya, n.d.). Effects of $\mathrm{pH}$ on fluoride sorption is studied in the $\mathrm{pH}$ range of 4.0 to 11.0 with a bio-adsorbent amount of $3.0 \mathrm{~g} / \mathrm{L}$, fluoride concentration of $3.0 \mathrm{mg} / \mathrm{L}$, and contact time of $120 \mathrm{~min}$ at $30{ }^{\circ} \mathrm{C}$. The $\mathrm{pH}$ of the fluoride solutions are adjusted by adding $0.1 \mathrm{M}\left(\mathrm{M}=\mathrm{mol} / \mathrm{dm}^{3}\right) \mathrm{HCl}$ and $0.1 \mathrm{M} \mathrm{NaOH}$ solutions. The effect of contact time (in minutes) is studied by taking a constant amount of adsorbent $(3 \mathrm{~g} / \mathrm{L})$ at $30{ }^{\circ} \mathrm{C}$ at time intervals of $5,10,15,30,60,90,120$, and $180 \mathrm{~min}$. The effect of adsorbent doses for fluoride removal is studied by taking adsorbent doses as $1,2,3,4$, and $5 \mathrm{~g} / \mathrm{L}$ at the contact time of $120 \mathrm{~min}$ at $30{ }^{\circ} \mathrm{C}$. Also, the effect of fluoride concentration on the defluoridation process of the adsorbent is studied taking the fluoride concentration as $3,6,9,12$, and $15 \mathrm{mg} / \mathrm{L}$. The amount of fluoride adsorbed per unit mass of the adsorbent $\left(q_{t}\right)$ at a time $t$ is calculated using the following equations.

$$
\begin{aligned}
& q_{t}(\mathrm{mg} / \mathrm{g})=\left(C_{o}-C_{t}\right) / \mathrm{m} \\
& \text { Extent of adsorption }(\%)=\left[\left(C_{o}-C_{t}\right) / C_{o}\right] \times 100
\end{aligned}
$$

where $C_{o}$ and $C_{t}$ are initial $(t=0)$ and final $(t=t)$ fluoride concentrations in milligrams per liter when the adsorption was carried out for a time interval of $t$ minutes, with an adsorbent amount of milligrams per liter.

\section{Cation exchange capacity}

Cation exchange capacity of PLP is determined by copper (II) bisethylenediamine complex method. In this method, $0.5 \mathrm{~g}$ of PLP is added in $25 \mathrm{~mL}$ of each of the solution of $0.05,0.03,0.02$, and $0.01 \mathrm{M}$ of $\left[\mathrm{Cu}(\mathrm{en})_{2}\right]^{+2}$ and centrifuged for $30 \mathrm{~min}$. After adsorption is over, the mixture is filtered off and the used $\left[\mathrm{Cu}(e n)_{2}\right]^{+2}$ is 


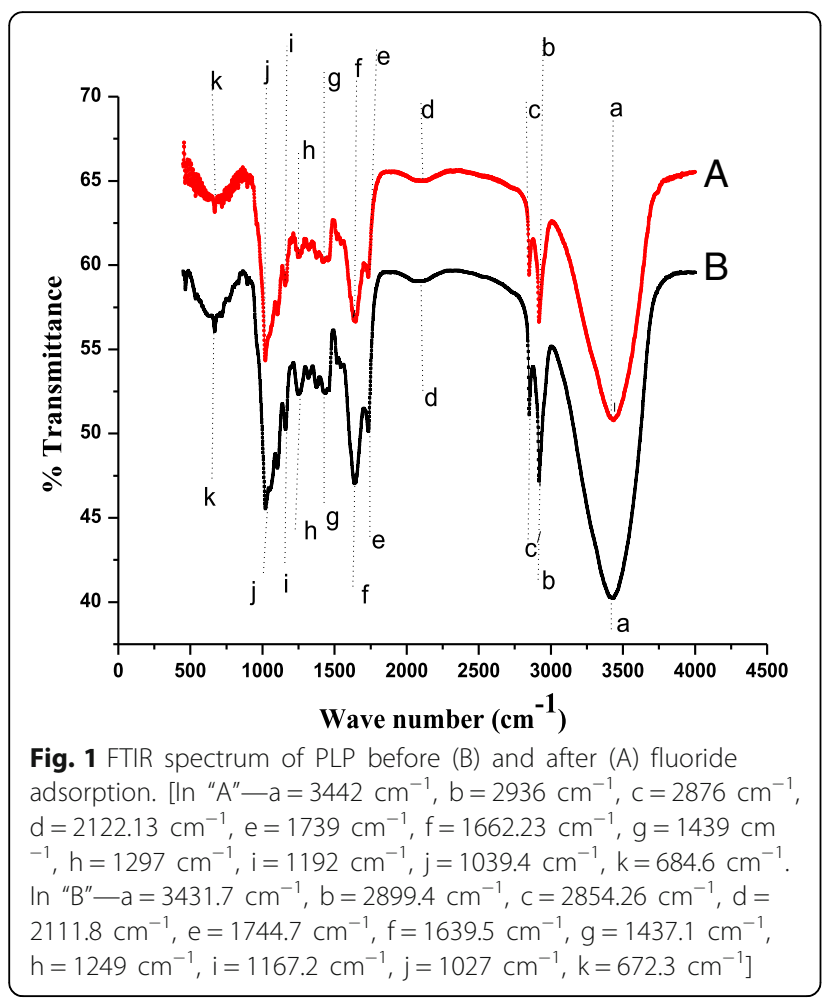

estimated spectrophotometrically using UV spectrometer at $\lambda_{\max }=550 \mathrm{~nm}$. The cation exchange capacity (CEC) of PLP is calculated using the equation:

$$
(\mathrm{meq} / \mathrm{g})=(M-S) / m
$$

where $M$ is the initial concentration of the solution, $S$ is the concentration of the solution after adsorption, and $m$ is the amount of the bio-adsorbent.

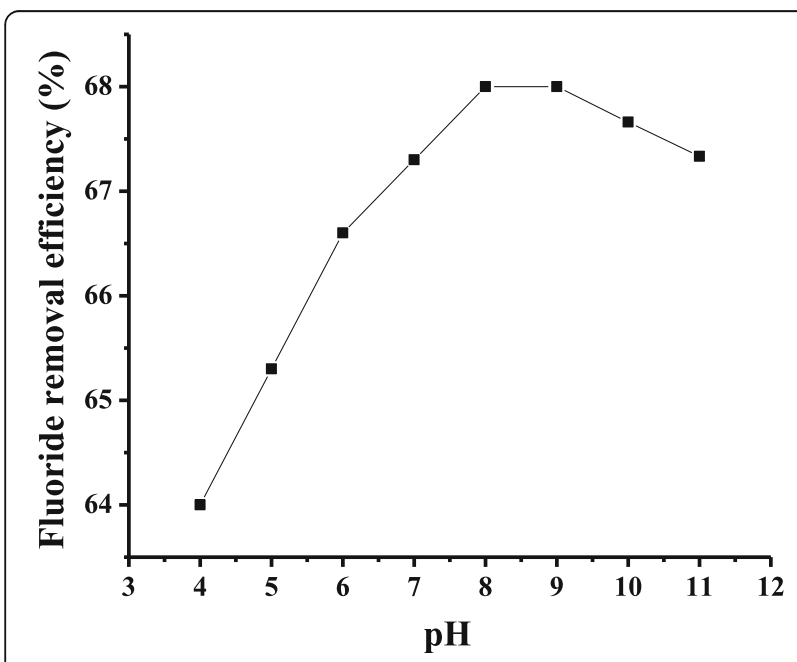

Fig. 2 Effect of $\mathrm{pH}$ on the removal efficiency of fluoride

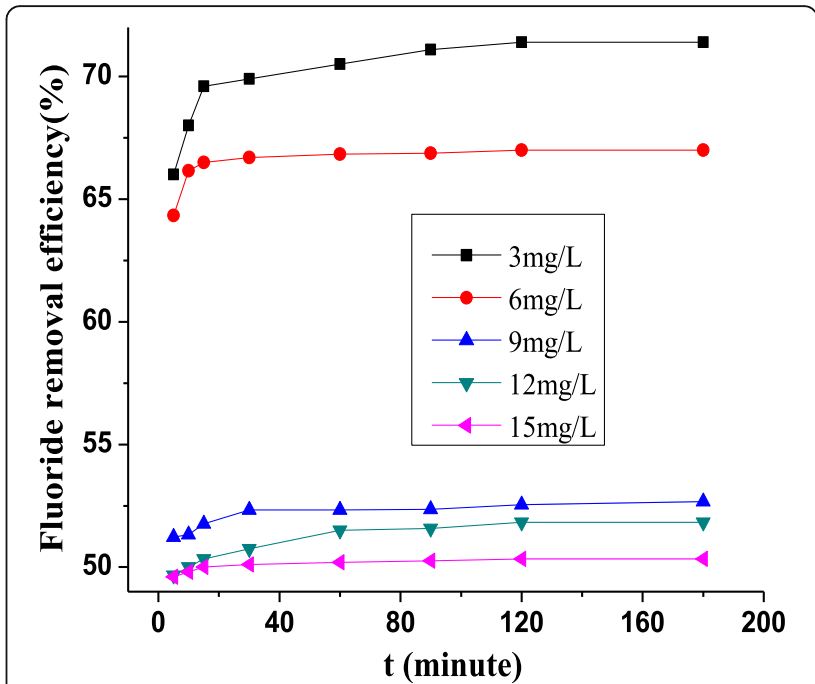

Fig. 3 Effect of contact time on the fluoride removal efficiency

\section{Anion exchange capacity}

To determine the anion exchange capacity (AEC), $0.1 \mathrm{M}$ $\mathrm{AgNO}_{3}$ and $0.01 \mathrm{M} \mathrm{NaCl}$ were prepared and titrated conductometrically. Again $0.1 \mathrm{M} \mathrm{AgNO}_{3}$ is titrated with the adsorbent solution containing $0.2 \mathrm{~g}$ adsorbent in $50 \mathrm{~mL}$ distilled water. Then using the following equation, AEC of PLP is calculated.

$$
(\mathrm{meq} / \mathrm{g})=N V / m
$$

where $N$ is the normality of $\mathrm{AgNO}_{3}, V$ is the volume difference of $\mathrm{AgNO}_{3}$ in two sets of titration, and $m$ is the amount of the bio-absorbent (anion exchanger).

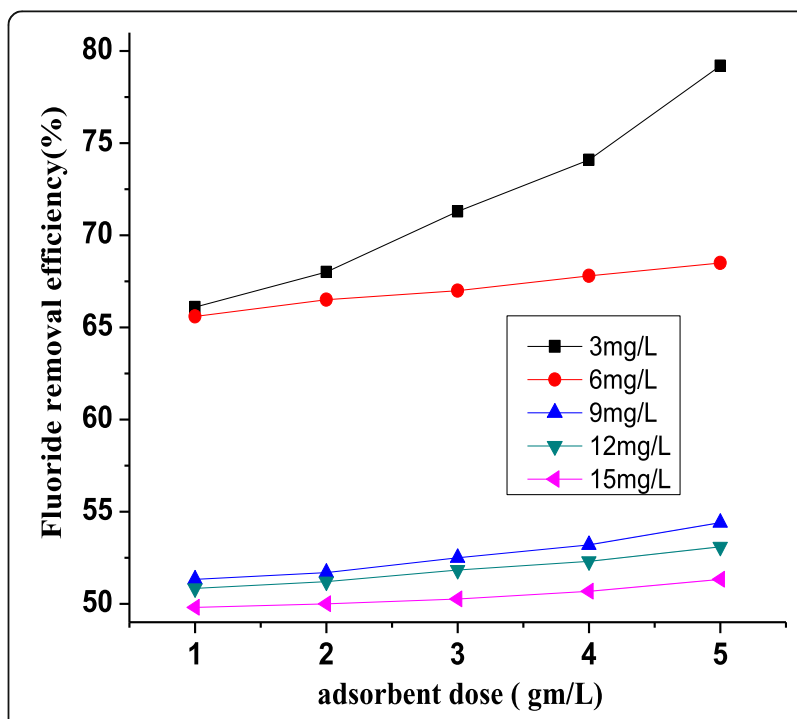

Fig. 4 Effect of adsorbent dose on the fluoride removal efficiency 


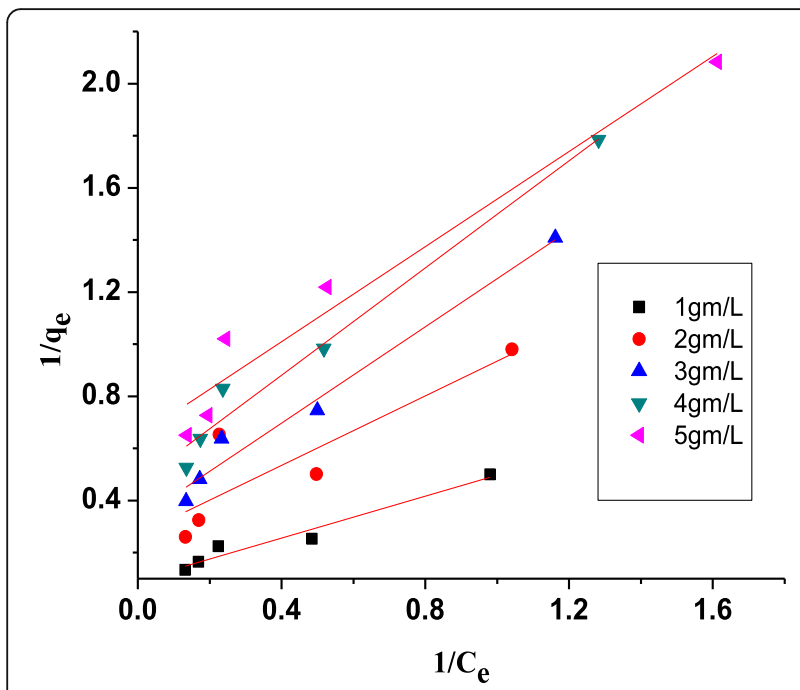

Fig. 5 Langmuir adsorption isotherm

\section{Results and discussion}

Identification of surface functional groups with IR spectroscopy

FTIR spectra of PLP before (B) and after (A) fluoride adsorption are presented in Fig. 1. The functional groups identified from the spectra are $-\mathrm{OH}(3431.7 \mathrm{~cm}$ $\left.{ }^{-1}\right),-\mathrm{CH}_{3}\left(2899.4\right.$ and $\left.2854.26 \mathrm{~cm}^{-1}\right), \mathrm{C}-\mathrm{C}, \mathrm{C}-\mathrm{N}<, \mathrm{C}-$ $\mathrm{O}-\left(1027\right.$ and $\left.1249.7 \mathrm{~cm}^{-1}\right),>\mathrm{C}=\mathrm{O}\left(1639.5 \mathrm{~cm}^{-1}\right)$, $>\mathrm{C}=\mathrm{S} \quad\left(1167.2 \mathrm{~cm}^{-1}\right), \quad-\mathrm{C} \equiv \mathrm{C}-\left(2111.8 \mathrm{~cm}^{-1}\right), \quad-\mathrm{CH}_{2}$ $\left(1427.1 \mathrm{~cm}^{-1}\right), \mathrm{C}=\mathrm{C}\left(1744.7 \mathrm{~cm}^{-1}\right)$, and $\mathrm{C}-\mathrm{X}\left(672.2 \mathrm{~cm}^{-1}\right)$. Comparing the FTIR spectra of PLP before (B) and after (A) fluoride adsorption, it is seen that the respective groups are shifted towards the higher value after fluoride adsorption. The chief cause of these shifts may be the interaction with fluoride.

\section{The effect of $\mathrm{pH}$}

Figure 2 represents the effect of $\mathrm{pH}$ on removal efficiency of fluoride of adsorbent dose $3 \mathrm{~g} / \mathrm{L}$ in $3 \mathrm{ppm}$ fluoride solution. The test solution is found to be slightly acidic (having $\mathrm{pH}=6.38$ ) which was changed during the experiment from $\mathrm{pH} 4$ to 11 . It is observed that adsorption efficiency increases as the $\mathrm{pH}$ increases and gets the maximum at a $\mathrm{pH}$ of 8 and then starts decreasing. The relatively lower adsorption of fluoride in the acidic range indicates the possibility of formation of weakly ionized hydrofluoric acid. The quick reduction of the amount of fluoride adsorption in the alkaline $\mathrm{pH}$ range (after attaining $\mathrm{pH} 8$ ) may be due to competition of hydroxyl ions with fluoride for adsorption sites of PLP (Swain et al., n.d.).

\section{The effect of contact time}

Figure 3 reflects that on increasing contact time, fluoride removal efficiency of the adsorbent increases up to $120 \mathrm{~min}$ and remains constant afterwards. This may be due to the fluoride ion deposition on the available adsorption site of the PLP. The initial fast adsorption could be the result of participation of specific functional groups and active surface sites of PLP which decreases towards the end of the experiments. The monolayer formation of fluoride ion on the PLP outer surface and diffusion into the inner surface plays a crucial role in this case (Jamode et al., n.d.).

\section{The effect of adsorbent dose}

During the experiment, the amount of adsorbent dose is varied from 1 to $5 \mathrm{~g} / \mathrm{L}$ for various concentrations of fluoride solutions $(3,6,9,12$, and $15 \mathrm{mg} / \mathrm{L})$ at a constant shaking time of $120 \mathrm{~min}$. It is seen from Fig. 4 that for each of the concentration of the fluoride solution, the adsorption efficiency of the adsorbent increases with increase of the adsorbent dose. This is due to increasing adsorbent site (Swain et al., n.d.).

\section{Adsorption isotherm}

The adsorption isotherm is nothing but a mathematical relationship between the amount adsorbed on the adsorbent surface and the pressure (in case of gaseous adsorbate) or the concentration (in case of liquid) of the adsorbate in equilibrium at a constant temperature. To describe the adsorbate-adsorbent interactions quantitatively and to study the effectiveness

Table 1 Equilibrium isotherm parameters of the defluoridation process

\begin{tabular}{|c|c|c|c|c|c|c|c|c|c|c|c|}
\hline \multirow[t]{3}{*}{ PLP dose (g/L) } & \multicolumn{7}{|c|}{ Langmuir isotherm } & \multicolumn{2}{|c|}{ Freundlich isotherm } & \multicolumn{2}{|c|}{ Temkin isotherm } \\
\hline & \multirow{2}{*}{$\begin{array}{l}a \\
(\mathrm{~mol} / \mathrm{g})\end{array}$} & \multirow[t]{2}{*}{$b(\mathrm{~L} / \mathrm{mg})$} & \multicolumn{5}{|l|}{$R_{L}$} & \multirow[t]{2}{*}{$\overline{1 / n}$} & \multirow[t]{2}{*}{$K(\mathrm{~L} / \mathrm{g})$} & \multirow{2}{*}{$\begin{array}{l}B \\
(\mathrm{~J} / \mathrm{mol})\end{array}$} & \multirow[t]{2}{*}{$A_{T}(\mathrm{~L} / \mathrm{g})$} \\
\hline & & & $3 \mathrm{mg} / \mathrm{L}$ & $6 \mathrm{mg} / \mathrm{L}$ & $9 \mathrm{mg} / \mathrm{L}$ & $12 \mathrm{mg} / \mathrm{L}$ & 15 mg/L & & & & \\
\hline 1 & 10.75269 & 26.41938 & 0.01246 & 0.006269 & 0.004188 & 0.003144 & 0.002517 & 0.598 & 2.118361 & 5.583 & 1.395779 \\
\hline 2 & 3.703704 & 5.577867 & 0.05639 & 0.029013 & 0.019531 & 0.01472 & 0.011811 & 0.532 & 1.08893 & 2.536 & 1.465255 \\
\hline 3 & 3.067485 & 3.319789 & 0.091246 & 0.047804 & 0.032385 & 0.024487 & 0.019686 & 0.54 & 0.810961 & 1.734 & 1.562499 \\
\hline 4 & 2.12766 & 2.067696 & 0.138829 & 0.074592 & 0.050996 & 0.038741 & 0.031235 & 0.504 & 0.656145 & 1.242 & 1.682087 \\
\hline 5 & 1.550388 & 1.701852 & 0.163785 & 0.089197 & 0.061287 & 0.04668 & 0.037696 & 0.462 & 0.594292 & 0.948 & 1.902833 \\
\hline
\end{tabular}




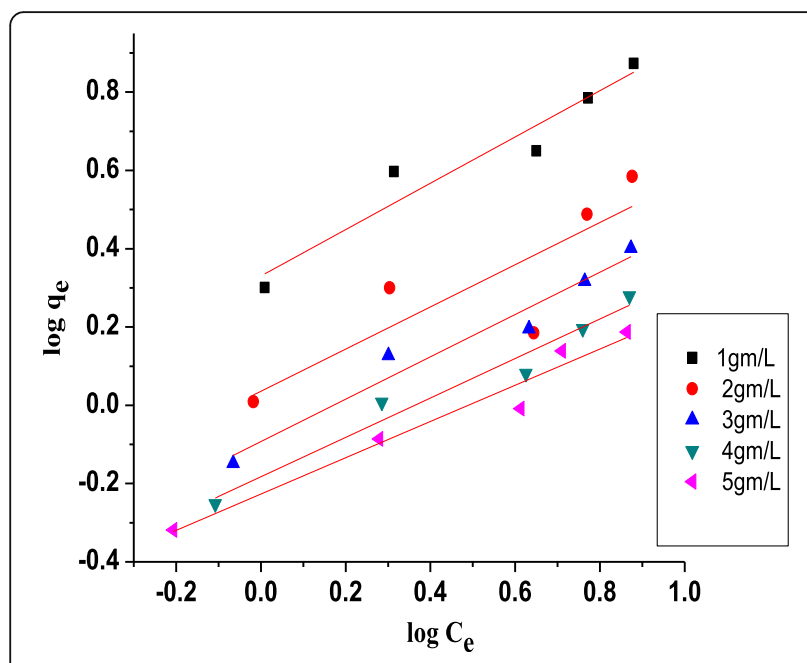

Fig. 6 Freundlich adsorption isotherm

of the absorbent for the particular adsorbate, the following adsorption isotherms have been evaluated.

\section{Langmuir isotherm}

For monolayer adsorption at specific homogeneous sites of adsorbent surface, the Langmuir isotherm is usually used. The Langmuir isotherm expression is:

$$
1 / q_{e}=(1 / a)+\left(1 / a b C_{e}\right)
$$

where, $C_{e}$ is the equilibrium concentration of the adsorbate in liquid phase, $a$ is the number of moles of solute adsorbed per unit weight of the adsorbent in forming a monolayer on the surface (Langmuir monolayer coverage), and $b$ is the constant related to the equilibrium

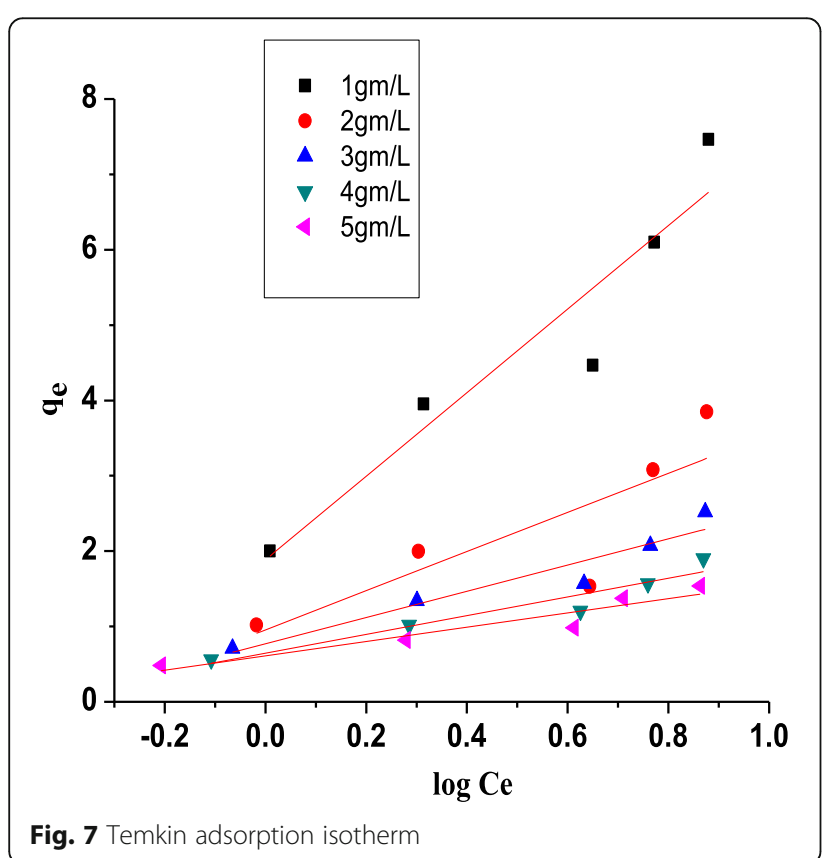

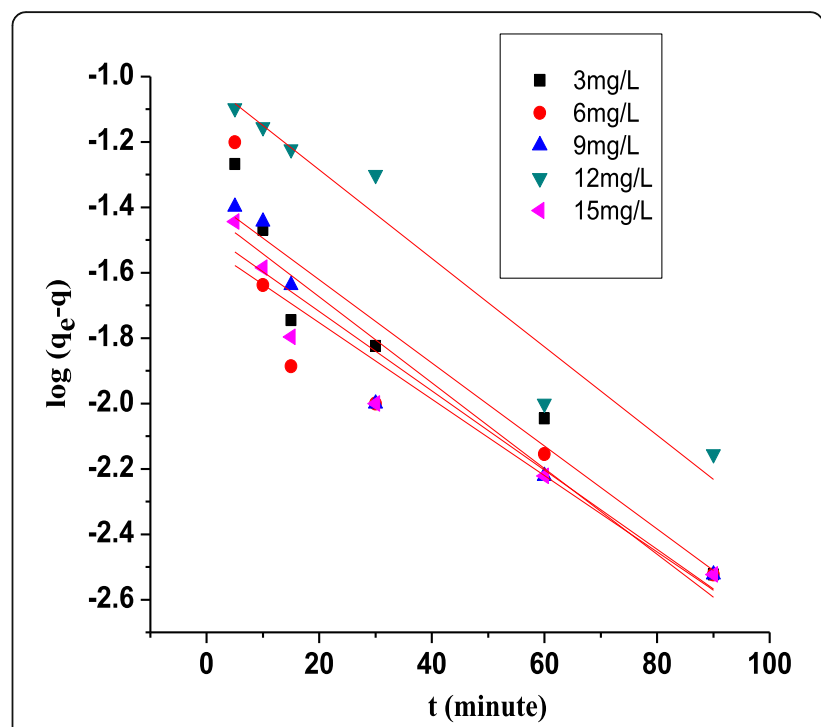

Fig. 8 Pseudo first-order kinetics

constant of adsorbate-adsorbent equilibrium. As shown in Fig. 5 , a plot of $1 / q_{e}$ versus $1 / C_{e}$ yields "a" and "b" as the slope and intercept, respectively (Table 1 ), which is comparable to the previously reported values of various bioadsorbents (Bharali et al., n.d.). To know whether the Langmuir-type adsorption is favorable or not, the separation factor $R_{L}$ is calculated using the equation:

$$
R_{L}=1 /\left(1+b C_{0}\right)
$$

where $b$ is the Langmuir coefficient $(\mathrm{L} / \mathrm{mg})$ and $C_{0}$ is the adsorbate initial concentration. For favorable adsorption,

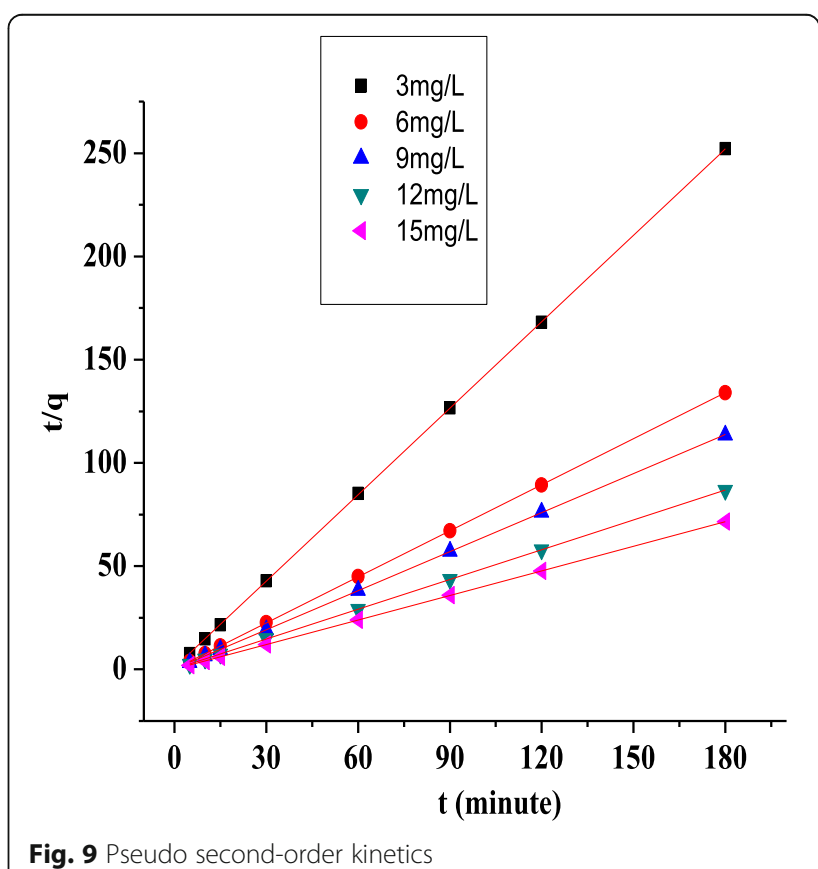


Table 2 Kinetic parameters of the pseudo first- and second-order kinetics

\begin{tabular}{|c|c|c|c|c|c|c|}
\hline \multirow{2}{*}{$\begin{array}{l}\text { Initial con } \\
(\mathrm{mg} / \mathrm{L})\end{array}$} & \multicolumn{2}{|c|}{ Pseudo 1st-order parameters } & \multirow[b]{2}{*}{$k_{1}\left(\min ^{-1}\right)$} & \multicolumn{2}{|c|}{ Pseudo 2nd-order parameters } & \multirow[b]{2}{*}{$k_{2}(\mathrm{~L} / \mathrm{mol} / \mathrm{min}$} \\
\hline & $q_{e}(\mathrm{mg} / \mathrm{g})$ & $q_{e}(\mathrm{mg} / \mathrm{g})$ from $\mathrm{plot}$ & & $q_{e}(\mathrm{mg} / \mathrm{g})$ & $q_{e}(\mathrm{mg} / \mathrm{g})$ from plot & \\
\hline 3 & 0.714 & 0.042954 & 0.027636 & 0.714 & 0.716332 & 2.388256 \\
\hline 6 & 1.343 & 0.033497 & 0.027636 & 1.343 & 1.345895 & 3.049995 \\
\hline 9 & 1.576 & 0.038815 & 0.029939 & 1.576 & 1.587302 & 1.593975 \\
\hline 12 & 2.07 & 0.096828 & 0.029939 & 2.07 & 2.079002 & 0.929161 \\
\hline 15 & 2.516 & 0.030269 & 0.025333 & 2.516 & 2.518892 & 3.353383 \\
\hline
\end{tabular}

the value of $R_{L}$ lies between 0 and 1 . While $R_{L}>1$ indicates unfavorable adsorption, $R_{L}=1$ indicates linear adsorption and $R_{L}=0$ indicates irreversible adsorption (Erhayem et al., n.d.-a). In this case, the value of $R_{L}$ (Table 1) indicates that the adsorption of fluoride on the PLP surface is favorable for the Langmuir model.

\section{Freundlich isotherm}

The Freundlich isotherm is generally applicable to physico-chemical adsorption on heterogeneous surface energy systems (non-uniform distribution of adsorption heat) (Erhayem et al., n.d.-a; Oladoja et al., n.d.). The linear form of the Freundlich adsorption isotherm is represented as:

$$
\log q_{e}=(1 / n) \log C_{e}+\log K_{f}
$$

where $K_{f}$ is the adsorption capacity, $n$ is the adsorption intensity (both $K_{f}$ and $n$ are known as the Freundlich constant), $q_{e}$ is the amount of solute adsorbed per unit mass of the adsorbent $(\mathrm{mg} / \mathrm{g})$, and $C_{e}$ is the equilibrium concentration of the adsorbate $(\mathrm{mg} / \mathrm{L})$.

A plot of $\log q_{e}$ versus $\log C_{e}$ (Fig. 6) gives a straight line in which the slope gives the value of $1 / n$ and the intercept gives the value of $K_{f}$ (Table 1 ) which is comparable to the previous reported values of various bio-

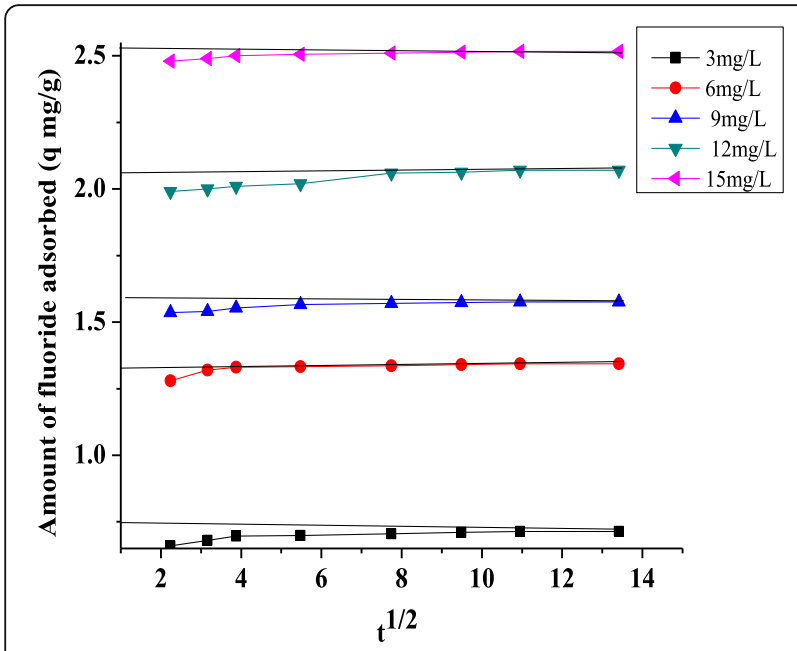

Fig. 10 Intra-particle diffusion adsorbents (Bharali et al., n.d.). The numerical value of $1 / n$ varies between 0 and 1 and is a measure of adsorption intensity or surface heterogeneity. The closer to zero value of $1 / n$ indicates surface heterogeneity. A value of $1 / n<1$ implies a chemisorption process whereas $1 /$ $n>1$ is indicative of cooperative adsorption.

In the present case, the $1 / n$ values lies between 0 and 1 (Table 1), and hence, fluoride adsorption on a PLP surface at a low concentration is favorable. The same magnitude of " $n$ " values suggests that the retention of fluoride from the solution takes place by ionic interactions.

\section{Temkin isotherm}

For heterogeneous surface energy systems (non-uniform distribution of adsorption heat), the Temkin isotherm is usually used. It helps in evaluating the adsorption potential of the adsorbent and adsorbed solution. The linearized form of the Temkin isotherm is:

$$
q_{e}=B \ln A_{T}+B \ln C_{e}
$$

where $A_{T}$ is the equilibrium binding constant $(\mathrm{L} / \mathrm{g}), b$ is

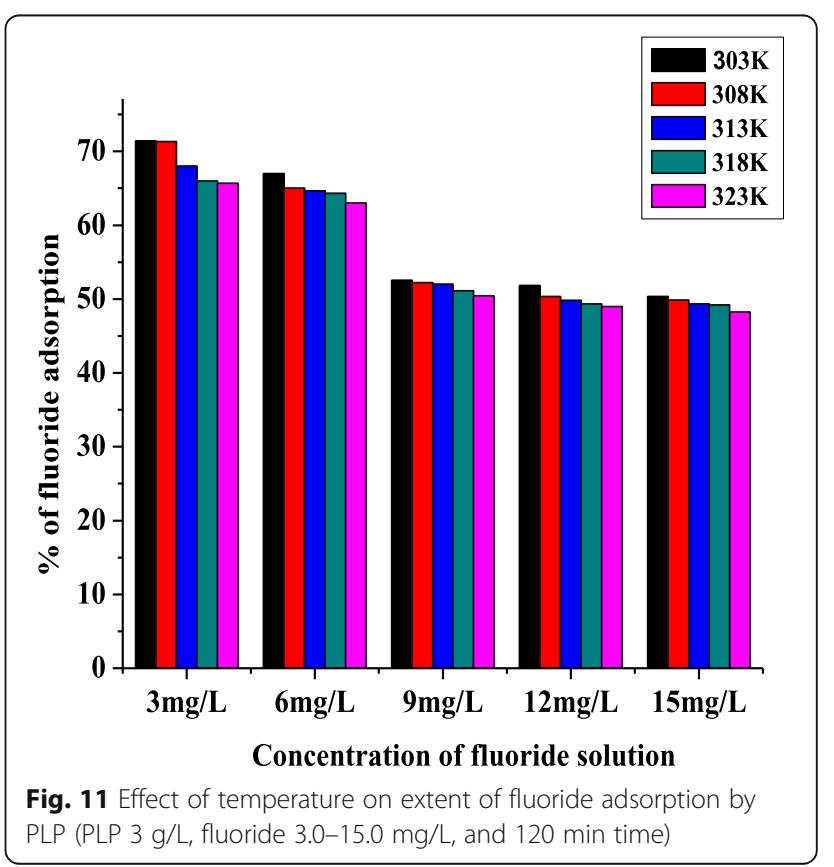




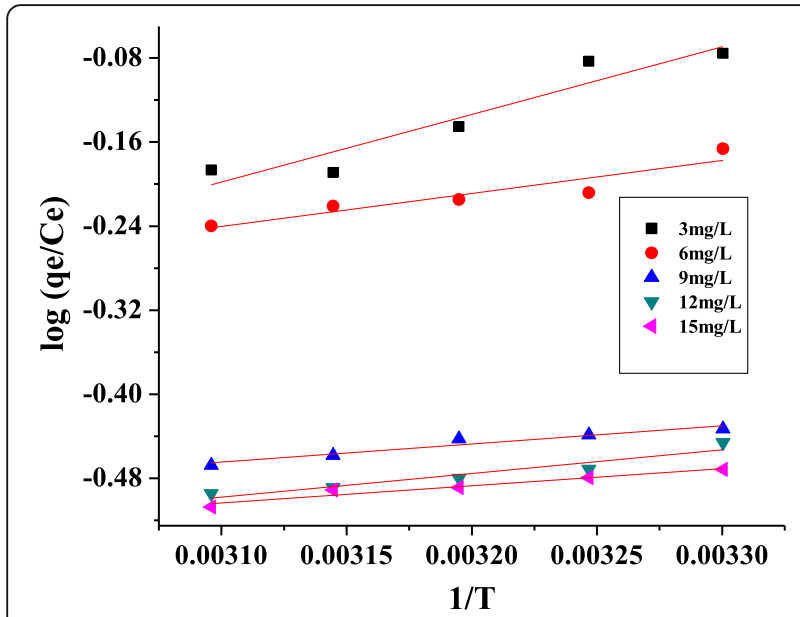

Fig. 12 van't Hoff plot of fluoride adsorption on PLP (PLP 3 g/L, fluoride $3.0-15.0 \mathrm{mg} / \mathrm{L}$, and $120 \mathrm{~min}$ time)

the adsorption constant $(\mathrm{J} / \mathrm{mol} \mathrm{K}), R$ is universal gas constant $(8.314 \mathrm{~J} / \mathrm{K} \mathrm{mol}), q_{e}$ is the amount of solute adsorbed per unit mass of the adsorbent $(\mathrm{mg} / \mathrm{g}), T$ is absolute temperature, and $B=(R T / b)$ is a constant related to the heat of adsorption $(\mathrm{J} / \mathrm{mol})$. As shown in Fig. 7, the slope of the linear plot of $q_{e}$ versus $\ln C_{e}$ gives the value of $B$ and the intercept gives the value of $A_{T}$. The result shows small value of $B$ (Table 1 ) which indicates weak interaction between adsorbent and adsorbate supporting a mechanism of ion exchange (Erhayem et al., n.d.-a; Oladoja et al., n.d.; Nechifore et al., n.d.).

\section{Adsorption kinetics}

Kinetic study on adsorption process is significant as it provides valuable information about the reaction pathways and the mechanism of sorption interactions. Besides, it describes the solute uptake rate which controls the residence time of the adsorbate at the solid-solution interface. Therefore, it is important to predict the rate at which a pollutant is removed from aqueous solutions for designing appropriate water treatment processes.

To fit the experimental data, Lagergren pseudo firstorder and pseudo second-order kinetic models are used. The pseudo first-order kinetic model is represented as

$$
\log \left(q_{e}-q_{t}\right)=\log q_{e}-\left(k_{1} / 2.303\right) \cdot t
$$

and the expression for the pseudo second-order kinetic model is

$$
t / q=1 / h+\left(1 / q_{e}\right) \cdot t, \text { here } h=k_{2} q_{e}^{2}
$$

where $q_{t}$ is the amount of fluoride adsorbed $(\mathrm{mg} / \mathrm{g})$ at time $t, q_{e}$ is the amount of fluoride adsorbed $(\mathrm{mg} / \mathrm{g})$ at equilibrium time, $k_{1}$ is the rate constant of the pseudo first-order kinetics, and $k_{2}$ is the rate constant of the pseudo second-order kinetics. In the plot of $\log \left(q_{e}-q_{t}\right)$ versus $t$, the intercept gives the value of " $q_{e}$ " in the pseudo first-order kinetics (Fig. 8).

In the plot of $t / q$ versus $t$, the slope gives the value of " $q_{e}$ " and the intercept $h$ (Fig. 9). The test of validity can be done by comparing the experimental $q_{e}$ value to the $q_{e}$ value obtained from the plot. The result (Table 2) reveals that the adsorption mechanism proceeds through pseudo second-order kinetics (Erhayem et al., n.d.-a).

\section{Intra-particle diffusion}

Adsorption is a multi-step process which involves the transport of the solute molecules from the aqueous phase to the surface of the adsorbent particles and then diffusion of the solute molecules into the interior of the pores which is likely to be a slow process and is therefore considered as a rate-determining step. The possibility of existence of intra-particle diffusion is tested by plotting a graph (Fig. 10) between amount of fluoride adsorbed $\left(q_{t}\right)$ and the square root of time from the following equation:

$$
q_{t}=X+K \cdot t^{1 / 2}
$$

The slope of linear portion of the plot gives the value of rate constant $K$. As could be observed from the figure, the linear portion of the plot does not pass through the origin indicating that the mechanism of fluoride adsorption is complex and both the surface adsorption and the intraparticle diffusion contribute to the rate-determining step

\begin{tabular}{|c|c|c|c|c|c|c|c|}
\hline \multirow{2}{*}{$\begin{array}{l}\mathrm{C}_{e} \\
\text { (mg/ } \\
\mathrm{L})\end{array}$} & \multirow[t]{2}{*}{$\Delta H(\mathrm{~J} / \mathrm{mol})$} & \multirow{2}{*}{$\begin{array}{l}\Delta S(\mathrm{~J} / \\
\mathrm{mol})\end{array}$} & \multicolumn{5}{|l|}{$\Delta G(\mathrm{~J} / \mathrm{mol})$} \\
\hline & & & $303 \mathrm{~K}$ & 308 K & $313 \mathrm{~K}$ & $318 \mathrm{~K}$ & $323 \mathrm{~K}$ \\
\hline 3 & $-12,307.998$ & -41.9467 & 401.8521 & 611.585 & 821.3191 & 1031.053 & 1240.786 \\
\hline 6 & -6001.4435 & -23.2063 & 1030.065 & 1146.097 & 1262.128 & 1378.16 & 1494.191 \\
\hline 9 & -3310.2682 & -19.2352 & 2517.997 & 2614.173 & 2710.349 & 2806.525 & 2902.701 \\
\hline 12 & -4312.0418 & -22.8999 & 2626.628 & 2741.127 & 2855.627 & 2970.126 & 3084.626 \\
\hline 15 & -3111.2314 & -19.262 & 2725.155 & 2821.465 & 2917.775 & 3014.085 & 3110.395 \\
\hline
\end{tabular}
(Bharali \& Bhattacharyya, n.d.).

Table 3 Values of thermodynamic parameters for fluoride adsorption on PLP 


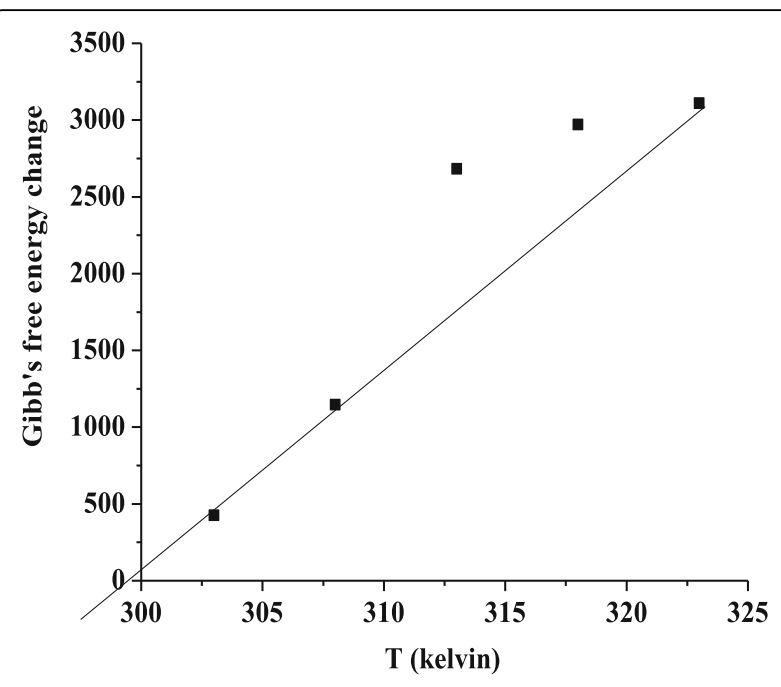

Fig. 13 Gibb's free energy change with temperature

\section{Adsorption thermodynamics}

Temperature plays a significant role in adsorption. In the present case, the effect of temperature is studied in five different temperatures of 303, 308, 313, 318, and $323 \mathrm{~K}$. Results reveal that on increasing temperature, the extent of fluoride adsorption on PLP decreases (Fig. 11). This may be due to decreasing adsorptive force between PLP and fluoride ions.

Thermodynamic parameters were calculated using the van't Hoff equation:

$$
\log \left(q_{e} / C_{e}\right)=\Delta S /(2.303 R)-\Delta H /(2.303 R T)
$$

where $\Delta S$ is the entropy change, $\Delta H$ is the enthalpy change, and $\left(q_{e} / C_{e}\right)$ is the adsorption affinity. From the intercept and slope of the plot of $\log \left(q_{e} / C_{e}\right)$ vs $1 / T$
(Fig. 12), $\Delta S$ and $\Delta H$ could be determined. Gibb's free energy change was calculated using the fundamental equation:

$$
\Delta G=\Delta H-T \Delta S
$$

where $\Delta G$ is Gibb's free energy change and $T$ is the respective absolute temperature.

From the result (Table 3), the negative values of $\Delta H$ indicate the exothermic nature of the adsorption process, the negative values of $\Delta S$ indicate a decrease in randomness at the PLP surface during the adsorption process, and the $\Delta G$ values point out the feasibility of adsorption in a low temperature (Fig. 13) which indicates the usefulness of this bio-adsorbent at room temperature (Islam \& Patel, 2007).

\section{Cation exchange capacity}

The ability to react with positively charged molecules is called the cation exchange capacity (CEC) of that substance. Higher CEC indicates the higher negative charge of the substance and hence can bind more cations. The cation exchange capacity of PLP is estimated to be 0.0074 (meq/g).

\section{Anion exchange capacity}

The anion exchange capacity (AEC) of a substance indicates the degree to which it can adsorb and exchange anions. The anion exchange capacity of PLP is estimated to be $1.25 \mathrm{meq} / \mathrm{g}$.

\section{SEM analysis}

The SEM micrographs of PLP samples before and after fluoride sorption are shown in Fig. 14 (PLP 1 and PLP 2 respectively). As could be seen in the micrographs, the surfaces of the particles of PLP are irregular and have

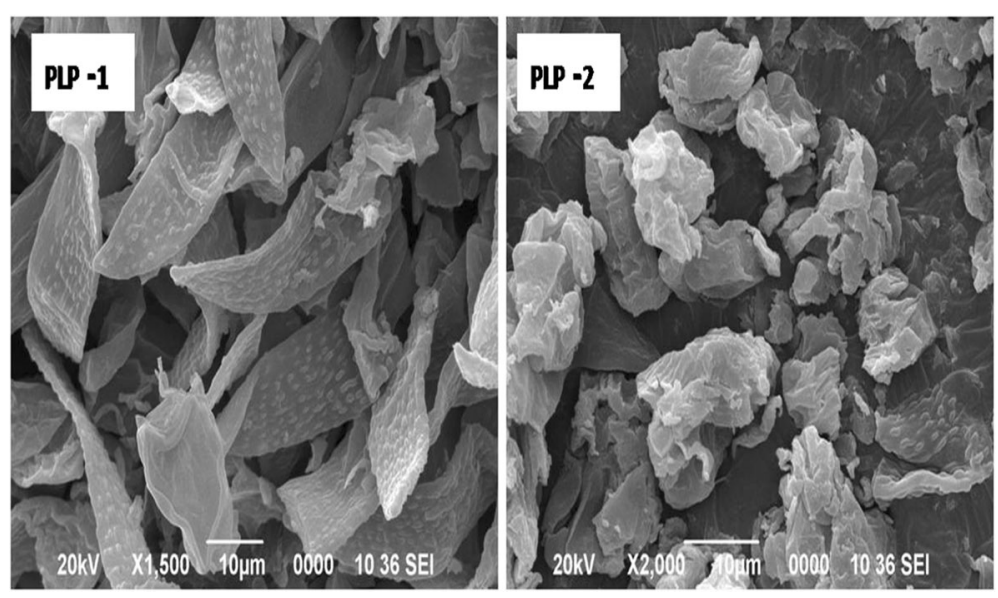

Fig. 14 SEM images of the leaves before (PLP-1) and after (PLP-2) adsorption 
broken edges. This may be the indication of higher surface area and higher adsorption capacity of PLP. After fluoride adsorption, surface morphologies of the PLP samples are somewhat swollen and there changes in the size of the particles. The change in the surface morphologies reveals that the process of fluoride adsorption on PLP is predominantly a surface phenomenon.

\section{Conclusions}

From the systematic study, the following conclusions could be drawn:

1. The PLP can remove more than $70 \%$ of fluoride from a 3-ppm aqueous solution on its own at a normal pH range, at a contact time of $120 \mathrm{~min}$ and $3 \mathrm{~g} /$ $\mathrm{L}$ of its dose.

2. Adsorption of fluoride by PLP follows a pseudo second-order mechanism, and the mechanism of fluoride removal is found to be complex. The surface adsorption as well as the intra-particle diffusion contributes to the rate-determining step.

3. Significant amount of fluoride can be removed in the $\mathrm{pH}$ range $7-8$ by using PLP, which makes it suitable to utilize in defluoridation of drinking water especially in rural areas where sophisticated facilities are not available.

4. It is a cost affordable, easily available, and environment-friendly bio-adsorbent.

5. Further studies need to be carried out for evaluation of the bio-adsorbent for reusability.

\section{Authors' contributions}

PS conceived of the study and contributed in design and organization of the manuscript. HKB carried out the adsorption and kinetic experiments. RKB helped in analysing the data. All authors read and approved thefinal manuscript.

\section{Competing interests}

The authors declare that they have no competing interests.

\section{Publisher's Note}

Springer Nature remains neutral with regard to jurisdictional claims in published maps and institutional affiliations.

Received: 1 October 2017 Accepted: 27 November 2017

Published online: 12 December 2017

\section{References}

Bharali RK, Bhattacharyya KG. Kinetic and thermodynamic studies on fluoride bisorption by devdaru (Polyalthia longifolia) leaf powder. Oct J Env Res. 2014;2:22-31.

Bharali RK, Bhattacharyya KG. Biosorption of fluoride on Neem (Azadirachta indica) leaf powder. J Environ Chem Eng. 2015;3:662-9.

Bhatnagar A, Kumar E, Sillanpaa M. Fluoride removal from water by adsorption —a review. Chem Eng J. 2011;171:811-40.

Bhaumik R, Mandal NK. Optimizing adsorption of fluoride from water by modified banana peel dust using response surface modelling approach. Appl Water Sci. 2016;6: 115-35.

Dharamasiri MG, Galhena G, Ratnasooriya WD. Anti-inflamatory and analgesic activities of mature fresh leaves of vitex negundo. J Ethnopharmacol. 2003; 87:199-206.
Erhayem M, Tohami FA, Mohamed R, Ahmida K. Isotherm, kinetics and thermodynamic studies for the sorption of Mercury (II) onto activated carbon from Rosmarinus officinalis leaves. Am J Anal Chem. 2015;6:1-10.

Gandhi N, Sirisha D, Shekhar KBC, Asthana S. Removal of fluoride from water and waste water by using low cost adsorbent. Int J ChemTech Res. 2012:4:1646-53.

Gupta RK, Tandon VR. Antinociceptive activity of vitex negundo Linn leaf extract. Indian J Physio Pharmacol. 2005:49:163-70.

Islam M, Patel RK. Evaluation of removal efficiency of fluoride from aqueous solution using quick lime. J Hazard Mater 2007;143:303-310.

Jamode AV, Sapkal VS, Jamode VS. Defluoridation of water using inexpensive adsorbents. J Indian Inst Sci. 2004;84:163-71.

Kumar S, Gupta A, Yadav JP. Removal of fluoride by thermally activated carbon prepared from neem(Azadirachta indica) and kikar (Acacia arabica) leaves. J Environ Biol. 2008;29:227-32

Levin S, Krishnan S, Rajkumar S, Halery N, Balkunde P. Monitoring of fluoride in water samples using a smartphone. SciTotal Environ. 2016;551-552:101-7.

Msagati TAM, Mamba BB, Sivasankar V, Omine K. Surface restructuring of lignite by bio-char of Cuminum cyminum-exploring the prospects in defluoridation followed by fuel applications. Appl Surf Sci. 2014;301:235-43.

Mamilwar BM, Bhole AG, Sudame AM. Removal of fluoride from ground water by using adsorbent. Int J Eng Res Appl. 2:334-8.

Mohan D, Sarma R, Singh VK, Steele P, C. Pittman U. Fluoride removal from water using bio-char, a green waste, low-cost adsorbent: equilibrium uptake and sorption dynamics modeling. Ind Eng Chem Res. 2012;51:900-14.

Mondal NK, Bhaumik R, Datta JK. Removal of fluoride by aluminium impregnated coconut fiber from synthetic fluoride solution and natural water. Alex Eng J. 2015; 54:1273-84.

Mondal P, Nandan A, Siddiqui NA, Yadav BP. Removal of fluoridefrom water by suitable low cost environmental friendly methods. Environ Pollut Cont J. 2014;17: 41-4.

Nechifore G, Pascu DE, Pascu M, Traistaru GA, Albu PC. Comparative study of Temkin and Flory-Huggins isotherm for adsorption of phosphate anion on membrane. U P B Sci Bull. 2015;77:63-9.

Oladoja NA, Chen S, Drewes JE, Helmreich B. Characterisation of granular matrix supported nano magnesium oxide as an adsorbent for defluoridation of ground water. Chem Eng J. 2015;281:632-43.

Ramanjaneyulu V, Jaipal M, Yasovardhan N, Sharada S. Kinetic studies on removal of fluoride from drinking water by using tamarind shell and pipal leaf powder. Int J EmerT Eng D. 2013;5:147-55.

Suneetha M, Syama Sundar B, Rabindranath K. Removal of fluoride from polluted waters using active carbon derived from barks of Vitex negundo plant. J Anal Sci Tecnol. 2003;6:15.

Swain SK, Mishra S, Patnaik T, Patel RK, Jha U, Dey RK. Fluoride removal performance of a new hybrid sorbent of $\mathrm{Zr}(\mathrm{IV})$-ethylenediamine. Chem Eng J. 2012;184:72-81.

Waghmare S, Arfin T. Fluoride removal by industrial, agricultural, and biomass wastes as adsorbents: review. Int J Adv Res I IE. 2015:1:628-53.

Yadav AK, Abbassi R, Gupta A, Dadashzadeh M. Removal of fluoride from aqueous solution and ground water by wheat straw, sawdust and activated bagasse carbon of sugarcane. Ecol Eng. 2011;52:211-8.

Yu X, Tong S, Ge M, Zuo J. Removal of fluoride from drinking water by cellulose@hydroxyapatite nanocomposites. Carbohyd Polym. 2013;92:269-75.

\section{Submit your manuscript to a SpringerOpen ${ }^{\mathcal{O}}$ journal and benefit from:}

- Convenient online submission

- Rigorous peer review

- Open access: articles freely available online

- High visibility within the field

- Retaining the copyright to your article

Submit your next manuscript at $>$ springeropen.com 